Audiology

Neurotology
Audiol Neurotol 2011;16:336-346

DOI: $\underline{10.1159 / 000322307}$
Received: July 29, 2010

Accepted after revision: October 8, 2010

Published online: December 24, 2010

\title{
The Histopathology of Revision Cochlear Implantation
}

\author{
Joonhan Lee ${ }^{a}$, b, e Donald K. Eddington ${ }^{a-d}$ Joseph B. Nadola, b, d \\ a Department of Otology and Laryngology, Harvard Medical School, ${ }^{b}$ Department of Otolaryngology, \\ Massachusetts Eye and Ear Infirmary, ' Cochlear Implant Research Laboratory, Massachusetts Eye and Ear Infirmary, \\ Boston, Mass., and d Speech and Hearing Bioscience and Technology Program, Division of Health Sciences and

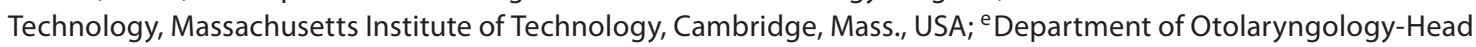 \\ and Neck Surgery, Chosun University, College of Medicine, Gwang Ju, South Korea
}

\section{Key Words}

Electrode track $\cdot$ Histopathology $\cdot$ Revision cochlear implantation

\begin{abstract}
The current study evaluates histopathologic changes in the temporal bones of 4 human subjects who underwent revision cochlear implantation. Specimens were removed at autopsy, fixed and prepared for histological study by standard techniques. Specimens were serially sectioned, reconstructed by two-dimensional methods, and the tracks of the initial and revision cochlear-implant electrodes identified. The tracks were of three types: a 'common track' (shared by the reimplantation electrode and initial electrode), 'two tracks' (where the reimplantation electrode was in a different track than that of the initial electrode) and 'one track' (where the reimplantation electrode extended beyond the initial electrode, forming a single track). Associated histopathologic findings (new bone formation, fibrosis or inflammatory cells, and cochlear fluid) were evaluated for the three types of tracks. In all 4 subjects, the insertion depth of the revision cochlear implant was deeper than that of the initial cochlear implant. The primary track of the initial implantation did not interfere with insertion of a revision cochlear implant, and the trajectory of the revision electrode did not always follow the primary track. In cochlear segments with a common
\end{abstract}

track or two tracks, the mean (across-subject) percent area of the extraelectrode cochlear duct filled with abnormal (new bone or fibrotic) tissue (43.2\%) was significantly greater than the mean percent area occupied by fluid $(13.4 \% ; \mathrm{t}=3.12$, d.f. $=19.9, p=0.003$ ).

Copyright $\odot 2010$ S. Karger AG, Basel

\section{Introduction}

As the number of cochlear implants done internationally has increased, there are increasing reports of revision cochlear implantation. Buchman et al. [2004] reported on 33 revision cochlear implantations in 30 patients, and resolution of the patient's presenting signs and symptoms occurred in nearly $90 \%$ of cases with significant improvement in auditory performance. Perioperative complications were uncommon. Sorrentino et al. [2009] reported on their experience with 20 revision implantations. They reported audiologic performance as stable or improved in $90 \%$ of cases. Rivas et al. [2008] reported on 48 revision cochlear implantations. Resolution of the preoperative symptoms was achieved in $83 \%$ of cases, and speech perception was lower in only 1 of the 48 cases. Notably, all cases in which communication with the internal device could not be established regained or surpassed previous peak performance, whereas in cases where performance 
decreased and a device malfunction was suspected, 75\% of patients did so, and these tended to be patients of age greater than 70 years. Cullen et al. [2008] reported on 93 revision cochlear implantations in pediatric patients. $\mathrm{Au}-$ ditory performance of the revision implant equaled or surpassed the best preoperative performance in 'most patients'. Zeitler et al. [2009] also reported a 'high rate' of surgical success in revision cochlear implantation with preservation or improvement of preoperative performance in the majority of patients and alleviation of preoperative symptoms. However, the clinical experience with revision cochlear implantation is not always as positive. Henson et al. [1999] reported on 28 adults who required cochlear reimplantation using the same implant design. In this study, $37 \%$ of patients had significantly higher sentence or word scores with their replacement cochlear implants, $26 \%$ had no significant change and $37 \%$ had significantly poorer scores.

Similarly Miyamoto et al. [1997] reported a retrospective study of 17 revision cochlear implantations. In most cases, insertion length and number of channels remained unchanged, but, based on a few patients in whom this was not the case, the mean depth of insertion was statistically lower in revision cases. Fayad et al. [2004] reported 5 complications in 43 reimplantations: 2 (5\%) intraoperative cerebrospinal fluid leaks and $3(7 \%)$ postoperative flap breakdowns with implant extrusion. The number of electrodes inserted was unchanged in 40 out of 43 patients, and speech perception remained stable or improved.

Likewise, Kang et al. [2009] reported 3 cases of incomplete extraction of the failed cochlear-implant electrode, resulting in intracochlear retention of a distal portion of the electrode array.

There has been little histopathologic study of the reimplanted temporal bone. In previous reports of cochlear histopathology in animals and humans, the reimplanted cochlea showed evidence of increased trauma [Shepherd et al., 1995], more new bone and fibrous tissue [Linthicum et al., 1991], and a significant increase in electrode insertion trauma in cases in which there was proliferation of granulation tissue at the cochleostomy [Jackler et al., 1989].

Rubinstein et al. [1998] presented the temporal-bone histopathology in 1 patient who underwent implantation of a single-channel electrode in the left ear and 4 years later underwent explantation and reimplantation with a conventional multichannel implant (same case as patient 4 in the current series). They identified two separate electrode tracks.

The Histopathology of Revision Cochlear Implantation
The current study characterizes the temporal-bone histopathology of 4 subjects who underwent at least one revision cochlear-implant surgery in life. We compare the tracks, insertion depth, and performance associated with the primary and revision implantations.

\section{Material and Methods}

The temporal bones were fixed in $10 \%$ buffered formalin, and decalcified in ethylenediaminetetraacetic acid. Those specimens in which the electrode array was left in situ were postfixed in $2 \%$ osmium tetroxide. All specimens were dehydrated in graded alcohols. The specimens in which the electrode array was left in situ were exchanged with propylene oxide and embedded in Araldite, whereas specimens in which the electrode array had been removed before fixation were embedded in celloidin. The embedded specimens were serially sectioned in the horizontal (axial) plane at an average thickness of $20 \mu \mathrm{m}$. Specimens embedded in Araldite with the electrode array left in situ were sectioned by a previously described technique [Nadol et al., 1994]. Every 10th section of specimen embedded in Araldite was either left unstained or stained in toluidine blue O. Every 10th section from specimens embedded in celloidin was stained with hematoxylineosin.

The serial sections were reconstructed by conventional twodimensional methods [Guild, 1921; Nadol, 1988; Schuknecht, 1993]. The total length of the cochlea and the depth of insertion of the electrode as measured from the round window were determined from two-dimensional reconstructions. The track of a cochlear-implant electrode was documented by direct microscopic observation when the electrode was cut in place or - in specimens in which the electrode had been removed prior to histological preparation - using histological evidence such as perielectrode fibrosis.

The electrode tracks were classified into three types based on their size, shape and trajectory. Nearest the cochleostomy, the initial and revision insertions always shared a common track. Longitudinal cochlear segments where the primary and revision electrodes took separate tracks were classified as two tracks. The presence of one track implies a single electrode. While following the tracks from the cochleostomy site to the tip of the electrode, transition from a common track to two single tracks was seen (subject 1, fig. 1, top panel). Transitions from a larger common track to a smaller single track were also observed (in subject 2, $13.2 \mathrm{~mm}$ from the round window in fig. 2, top panel; in subject $3,12.8 \mathrm{~mm}$ from the round window in fig. 3, top panel). The track of an Ineraid electrode (subject 2) was oval or bilobed, and was thus easily distinguished from the track of a Nucleus electrode.

In cases with two tracks, the track with an electrode in situ was judged to be the revision track (subjects $1,2,3$ ) whereas the other, with no electrode, was judged to be the primary track. If both tracks were empty (because of removal of the electrode at the time of histologic preparation, subject 4), the larger track was assumed to contain the multichannel electrode and the smaller track to have contained the single-channel electrode. Subject 2 was implanted 3 times (Ineraid, Ineraid, Nucleus 22). In this case, the size and shape of the Ineraid and Nucleus 22 tracks were distinguished 


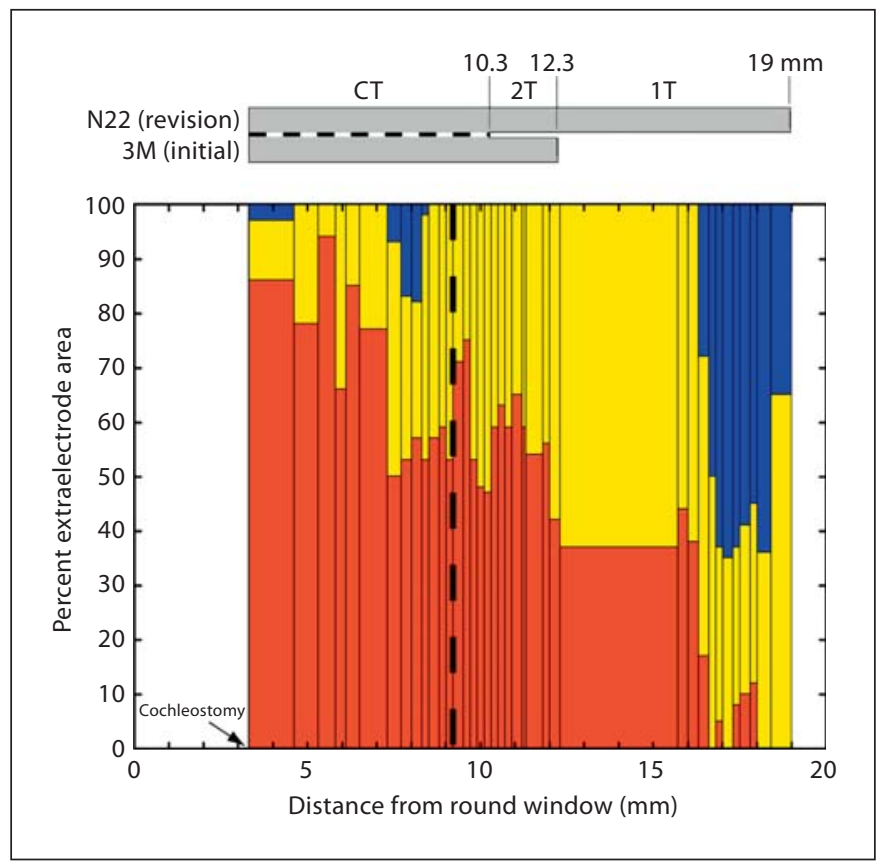

Fig. 1. Subject 1. Top panel: schematic representation of the type of electrode track as a function of distance from the round window. From the cochleostomy to $10.3 \mathrm{~mm}$, the $3 \mathrm{M}$ House single electrode (3M) and the Nucleus 22 (N22) revision electrodes occupied a common electrode track (CT). From 10.3 to $12.3 \mathrm{~mm}$, two separate electrode tracks were identified (2T). A single track (1T) extended from 12.3 to $19 \mathrm{~mm}$. Bottom panel: Plot of the percentage extraelectrode area occupied by new bone (red), fibrous/inflammatory tissue (yellow) and fluid (blue) as a function of distance from the round window. The solid vertical lines mark the boundaries between cochlear segments represented by the histological sections of the cochlear duct used to estimate the percentages. The weighted (see Methods) mean data of table 2 and the statistical analyses were computed from the cochlear segments apical to the dashed vertical line marking the location $5 \mathrm{~mm}$ apical from the apical margin of the cochleostomy. In this case, the cochleostomy extended from 3.3 to $4.2 \mathrm{~mm}$ from the round window.

by referring to other temporal-bone specimens implanted with similar multichannel devices. In this subject, the tracks of the first Ineraid and second Ineraid electrodes could not be distinguished. However, the operative record described the insertion depth of both primary and revision Ineraid electrodes as nearly the same. In subject 3 , the primary and revision electrodes were both $\mathrm{Nu}$ cleus 22 and the different insertion depths were supported by information in the operative record. Thus, a total of 14 electrode contacts of the primary implant were inserted and resistance was encountered $10 \mathrm{~mm}$ within the cochlea. The common track and the more apical single track (occupied by the revision cochlear implant) were distinguishable based on differences in size and shape of the tracks. In subject 4 , in whom the scala media was dilated by endolymphatic hydrops, the electrode track could be identified by the presence of perielectrode fibrosis.

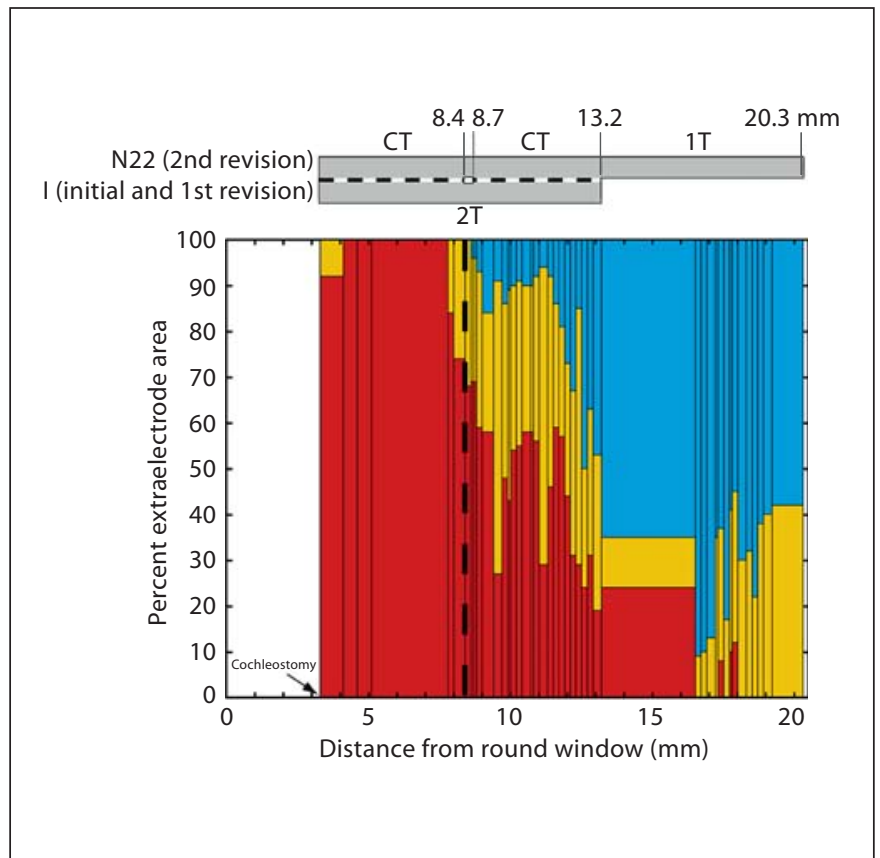

Fig. 2. Subject 2. See figure 1 caption for general information. Top panel: from the cochleostomy to $8.4 \mathrm{~mm}$, the Ineraid (I) initial and first-revision electrodes and the Nucleus 22 (N22) second-revision electrode occupied a common track (CT). From 8.4 to $8.7 \mathrm{~mm}$, two separate tracks were identified (2T). From 8.7 to $13.2 \mathrm{~mm}$, the Ineraid initial and first-revision electrodes and the Nucleus $22 \mathrm{sec}-$ ond-revision electrode again occupied a common track. A single track extended from 13.2 to $20.3 \mathrm{~mm}$. Bottom panel: the cochleostomy extended from 3.3 to $3.4 \mathrm{~mm}$ from the round window.

To compare the amount of perielectrode space occupied by new bone, fibrosis or cochlear fluid across the three types of tracks, every 10th section was magnified with a microprojector $(\times 15.6)$, and, for each cochlear turn with an electrode track, the cross-section of the turn, the electrode track, and regions of new bone, fibrosis, inflammatory cells and fluid were traced on graph paper $(250 \times 180 \mathrm{~mm})$. The perielectrode area of each cochlear turn represented by each histological section was computed by subtracting the area of the electrode track from the turn's cross-sectional area. The areas occupied by new bone, fibrosis, inflammatory cells or cochlear fluid were calculated for each turn and the percentage of the perielectrode area of each, computed by dividing the area for each tissue by the perielectrode area and multiplying by 100 . The percentages for each histological section were weighted by the longitudinal length represented by each turn of each segment and summed across section by tissue type, track type and subject, to compute the weighted mean percentage of the perielectrode space occupied by each tissue for each track type and subject.

The performance (NU-6) measures after the initial and revision cochlear implantations were available in some subjects, and in others an NU-6 score was estimated from other speech reception test results based on a technique described by Rabinowitz et al. [1992] (table 1). 


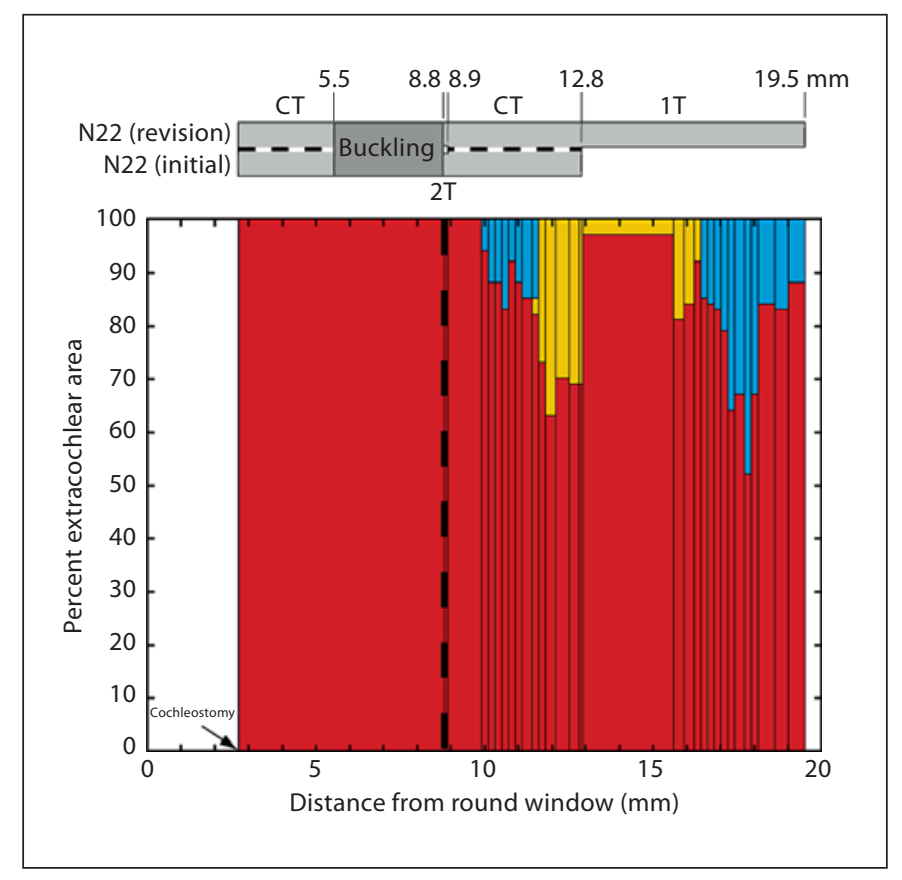

Fig. 3. Subject 3. See figure 1 caption for general information. Top panel: from the cochleostomy to $5.5 \mathrm{~mm}$, the Nucleus 22 (N22) primary electrode and the Nucleus 22 revision electrode occupied a common track (CT). From 5.5 to $8.8 \mathrm{~mm}$, buckling of the electrode occurred, and from 8.8 to $8.9 \mathrm{~mm}$, two separate tracks were identified (2T). From 8.9 to $12.8 \mathrm{~mm}$, the Nucleus 22 primary electrode and the Nucleus 22 revision electrode again occupied a common track. A single track (1T) extended from 12.8 to 19.5 $\mathrm{mm}$. Bottom panel: the cochleostomy extended from 2.7 to 3.8 $\mathrm{mm}$ from the round window.

\section{Results}

\section{Clinical Demographics}

The cause of deafness was a temporal bone fracture in 2 subjects, mumps and/or chemotherapy in 1 subject, and measles and chronic otitis media in 1 subject. In 2 subjects (subjects 1,4), the first cochlear implant was a singlechannel device that was replaced by a multichannel device at revision cochlear implantation. Details of the clinical demographics are shown in table 1 in outline form and presented in more detail in the following case reports.

\section{Case Reports}

\section{Subject 1}

In this 80 -year-old woman, hearing loss was first noticed on the right at age 4 years following an episode of measles and on the left at age 42 . There was a progressive loss of hearing in both ears over the years, and she was profoundly deaf at age 50. Otorrhea
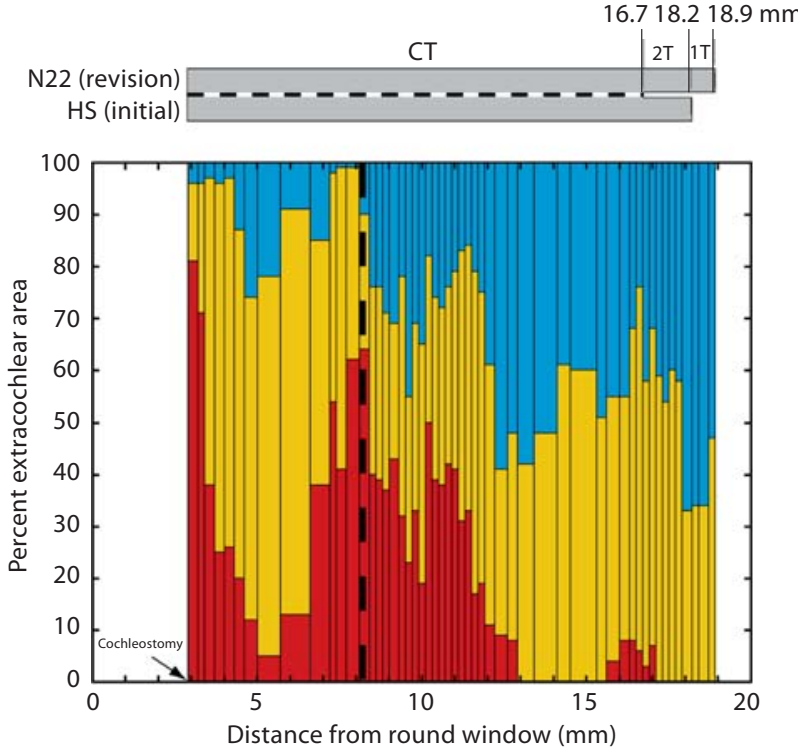

Fig. 4. Subject 4. See figure 1 caption for general information. Top panel: from the cochleostomy to $16.7 \mathrm{~mm}$, the House single-channel (HS) primary electrode and the Nucleus 22 (N22) revision electrode occupied a common track (CT). From 16.7 to $18.2 \mathrm{~mm}$, two separate tracks were identified (2T). A single track (1T) extended from 18.2 to $18.9 \mathrm{~mm}$. Bottom panel: the cochleostomy extended from 2.9 to $3.2 \mathrm{~mm}$ from the round window.

was first noted on the right side at age 40 and on the left side at age 42. She underwent mastoidectomy of the right ear at age 40 with revision on the right at age 64. Mastoidectomy of the left ear was done at age 67 . She underwent a right cochlear implantation using a $3 \mathrm{M}$ House single-channel device at age 65 , but 9 years later, that implant began to malfunction. At age 74 , the single-channel device was explanted, and a Nucleus 22 device was reimplanted.

\section{Subject 2}

This 88-year-old man had normal hearing until he sustained a skull fracture at age 70 . After recovery from the injury, he had '20\%' residual hearing. Residual hearing was lost 5 months later after a second skull fracture. He underwent a right cochlear implantation using an Ineraid device at age 71. One year later, the pedestal of the implant was sheared off while the patient was getting out of an automobile. He then underwent reimplantation on the right with another Ineraid device at age 72 . His second pedestal was also damaged, and he therefore underwent a second reimplantation using a Nucleus 22 device at age 75 .

\section{Subject 3}

This 79-year-old woman was profoundly deaf in the left ear from early in life; her deafness was attributed to mumps or polio. A progressive hearing loss in the right ear started at age 20 with a significant additional loss in hearing at age 72 while on chemo- 
Table 1. Clinical demographics of revision cochlear implantation

\begin{tabular}{|c|c|c|c|c|c|c|}
\hline Subject & $\begin{array}{l}\text { Sex/age } \\
\text { at death }\end{array}$ & $\begin{array}{l}\text { Cause of deafness or } \\
\text { indication for reimplantation }\end{array}$ & $\begin{array}{l}\text { Device and } \\
\text { age at surgery }\end{array}$ & $\begin{array}{l}\text { Duration of } \\
\text { use, months }\end{array}$ & $\begin{array}{l}\text { Depth of } \\
\text { insertion, mm }\end{array}$ & $\begin{array}{l}\text { Performance after } \\
\text { cochlear implantation }\end{array}$ \\
\hline $\begin{array}{l}\text { Subject } 1 \\
\text { (right ear) }\end{array}$ & $\mathrm{F} / 80$ & $\begin{array}{l}\text { measles and chronic otitis } \\
\text { media }\end{array}$ & $\begin{array}{l}\text { 3M House single- } \\
\text { channel device (65) }\end{array}$ & 120 & 12.3 & no record \\
\hline$\overline{\text { Revision } 1}$ & & malfunction of device & Nucleus $22(74)$ & 70 & 19 & NU6 words: 4\% \\
\hline $\begin{array}{l}\text { Subject } 2 \\
\text { (right ear) }\end{array}$ & $\mathrm{M} / 88$ & temporal bone fracture & Ineraid (71) & 17 & 13.2 & NU6 words: $11 \%^{1}$ \\
\hline Revision 1 & & $\begin{array}{l}\text { sheared off the pedestal of the } \\
\text { implant }\end{array}$ & Ineraid (72) & 30 & 13.2 & NU6 words: $10 \%$ \\
\hline Revision 2 & & $\begin{array}{l}\text { subsequently broke pedestal } \\
\text { for second time }\end{array}$ & Nucleus 22 (75) & 153 & 20.3 & NU6 words: $26 \%$ \\
\hline $\begin{array}{l}\text { Subject } 3 \\
\text { (right ear) }\end{array}$ & $\mathrm{F} / 79$ & mumps, chemotherapy & Nucleus 22 (75) & 13 & 12.8 & NU6 words: $2 \%$ \\
\hline Revision 1 & & poor word recognition & Nucleus $22(76)$ & 31 & 19.5 & NU6 words: $16 \%$ \\
\hline $\begin{array}{l}\text { Subject } 4 \\
\text { (left ear) }\end{array}$ & $\mathrm{M} / 67$ & temporal bone fracture & $\begin{array}{l}\text { House single-channel } \\
\text { device (53) }\end{array}$ & 54 & 18.2 & $\begin{array}{l}12 \text { closed-set words: } 50 \% \\
\text { environmental noises: } 80 \%\end{array}$ \\
\hline Revision 1 & & intermittent performance & Nucleus 22 (57) & 117 & 18.9 & $\begin{array}{l}\text { CID sentences: } 4 \% \text { NU6 } \\
\text { words: } 0 \%^{1}\end{array}$ \\
\hline
\end{tabular}

In all 4 subjects, the depths of revision electrodes were deeper than those of the initial electrodes

${ }^{1}$ Indicates word score estimated by the method of Rabinowitz et al. [1992].

therapy for metastatic lung carcinoma. She was profoundly deaf at age 75 , when she underwent a right cochlear implantation using a Nucleus 22 device. At surgery, resistance to insertion was encountered in the ascending basal turn. The cochleostomy was enlarged in an attempt to insert the electrode into the scala vestibuli. Resistance was encountered at the same location, and only half of the electrodes were inserted. A postoperative plain X-ray showed the implant to be in the cochlea with a small bend at its tip where the electrode curled back on itself. Performance was poor with this implant and a CT scan, 1 year after implantation, showed that the electrode array was only partially inserted. Therefore, at age 76, she underwent a revision right cochlear implantation using a Nucleus 22 device. Her word recognition improved from 2 to $16 \%$ (NU6).

\section{Subject 4}

This 67-year-old man became profoundly deaf bilaterally as a consequence of bilateral temporal bone fractures at age 47. Audiometry showed no response in both ears at age 50. At age 53, he underwent a left cochlear implantation using a House singlechannel device, but, because of intermittent performance with this device, he underwent explantation and reimplantation using a Nucleus 22 device at age 57 . The performance after the second implantation was similar to that after the first implantation (table 1).

\section{Insertion Depths and Tracks}

The insertion depth of each revision cochlear implant was greater than that of the initial cochlear implant in all
4 patients (fig. 1-4). The mean depth of insertion of the revision electrodes $(19.4 \mathrm{~mm})$ was significantly greater $(\mathrm{t}=-3.8$, d.f. $=3.3, \mathrm{p}=0.014)$ than that of the initial electrodes $(14.0 \mathrm{~mm})$. The trajectory of the revision electrode did not always follow the primary track. In all cases, the revision electrode started within the common track and then diverged to create another track.

In subject 1, the revision electrode (Nucleus 22) shared a common track with the $3 \mathrm{M}$ House single-channel device to a depth of $10.3 \mathrm{~mm}$ and then diverged to another trajectory, resulting in two tracks. The track of the $3 \mathrm{M}$ House single-channel electrode was no longer visible after $12.3 \mathrm{~mm}$ and the track of the Nucleus 22 electrode could be followed to $19 \mathrm{~mm}$ (fig. 1, 5-7).

In subject 2, the last revision electrode (Nucleus 22) followed the track created by the two Ineraid electrodes to $13.2 \mathrm{~mm}$ in depth, except for a short segment $(0.3 \mathrm{~mm})$ with two tracks, present between 8.4 and $8.7 \mathrm{~mm}$ from the round window (fig. 2, 8), and then diverged into another track and terminated at $20.3 \mathrm{~mm}$.

In subject 3, the revision electrode (Nucleus 22) entered the previous track created by the initial Nucleus 22 device to $12.8 \mathrm{~mm}$ in depth and then diverged to create a single new track to $19.5 \mathrm{~mm}$ in depth. A $3-\mathrm{mm}$ segment of buckled electrode was found within the common track 
Table 2. Percentage of area occupied by new bone, fibrosis, inflammatory cells and cochlear fluid in the extraelectrode space according to type of track

\begin{tabular}{|c|c|c|c|c|c|c|c|c|c|}
\hline & \multicolumn{3}{|c|}{ New bone formation, $\%$} & \multicolumn{3}{|c|}{ Fibrosis or inflammatory cells ${ }^{1}, \%$} & \multicolumn{3}{|c|}{ Cochlear fluid, \% } \\
\hline & common track & 2 tracks & 1 track & common tack & 2 tracks & 1 track & common track & 2 tracks & 1 track \\
\hline Subject 1 & 60 & 56.2 & 24.4 & 40 & 43.8 & 54.9 & 0 & 0 & 20.7 \\
\hline Subject 2 & 44.1 & 68.3 & 11.9 & 37.9 & 30.3 & 21.4 & 17.9 & 1.3 & 66.7 \\
\hline Subject 3 & 84.8 & 100 & 86.4 & $9.8^{1}$ & 0 & $3.5^{1}$ & 5.4 & 0 & 10.1 \\
\hline Subject 4 & 18 & 1.3 & 0 & 45.4 & 52.9 & 37.7 & 36.6 & 45.8 & 62.3 \\
\hline
\end{tabular}

${ }^{1}$ Indicates percentage of space occupied by inflammatory cells.

beginning about $5.5 \mathrm{~mm}$. The common track split into two tracks for a short segment $(0.1 \mathrm{~mm}$ ) at $8.8 \mathrm{~mm}$ (fig. $3,9)$.

In subject 4 , the revision electrode (Nucleus 22) followed the track created by the House single-channel device to $16.7 \mathrm{~mm}$ in depth and then diverged to create a short segment $(1.5 \mathrm{~mm})$ with two tracks, and finally continued as a short segment $(0.7 \mathrm{~mm})$ of one track (fig. 4,10$)$.

In the 4 subjects, the points of divergence from the common track to two tracks (subjects 1,4 ) or one track (subjects 2,3) were at $10.3 \mathrm{~mm}$ (midpoint of ascending basal turn) in subject 1, at $13.2 \mathrm{~mm}$ (endpoint of ascending basal turn) in subject 2, at $12.8 \mathrm{~mm}$ (endpoint of ascending basal turn) in subject 3 , and at $16.7 \mathrm{~mm}$ (midpoint of descending basal turn) in subject 4 , as measured from the round window. In all 4 subjects, the last single track was assumed to have been occupied by the revision electrode. The differences between the insertion depths of the revision and primary electrode tracks were +6.7 $\mathrm{mm}$ (subject 1), $+7.1 \mathrm{~mm}$ (subject 2$),+6.7 \mathrm{~mm}$ (subject 3 ) and $+0.7 \mathrm{~mm}$ (subject 4$)$.

\section{Histopathology of Extraelectrode Space}

The histopathology of all 4 specimens showed evidence of trauma to the inner ear structures, presumably caused by electrodes. In subject 1 , the initial electrode track passed through the basilar membrane from one scala to another scala at two locations $(8.8$ and $10.3 \mathrm{~mm})$ and the revision electrode track at one location $(12 \mathrm{~mm})$. In addition, dissection of the spiral ligament to the bony cochlear wall was also found (fig. 5-7).

In subjects 2 and 4 , the electrode track penetrated the basilar membrane at two separate locations, and dissection of the spiral ligament was found (fig. 8, 10). In subject 2 , the first and second Ineraid electrodes did not penetrate the basilar membrane, but the revision Nucleus 22

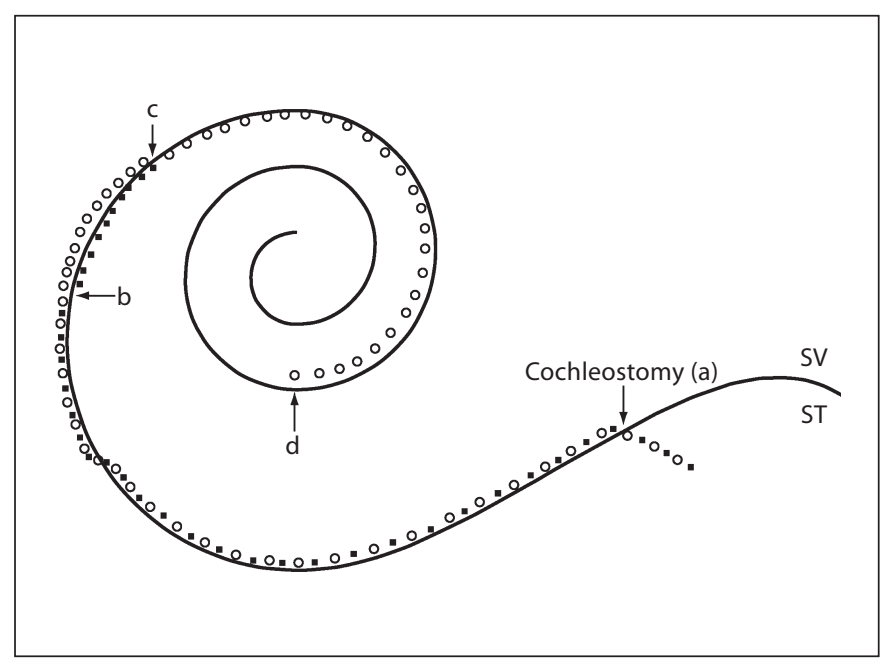

Fig. 5. Example of a two-dimensional reconstruction of the cochlea and electrode tracks (subject 1). The primary electrode track (3M House single-channel device) is shown by the filled black squares and the revision electrode track (Nucleus 22) is shown by open circles. There was a common track between a and b, two tracks between $b$ and $c$, and one track between $c$ and $d$. The distances along the cochlear duct of each point were: $3.3 \mathrm{~mm}$ (a), $10.3 \mathrm{~mm}$ (b), $12.3 \mathrm{~mm}$ (c) and $19 \mathrm{~mm}$ (d), as measured from the round window. $\mathrm{SV}=$ Scala vestibuli; $\mathrm{ST}=$ scala tympani.

electrode did so at two separate locations (16.5 and 19.3 $\mathrm{mm}$ ). In subject 4 , the initial electrode penetrated the basilar membrane at $8.2 \mathrm{~mm}$ and the revision electrode penetrated the basilar membrane at $16.5 \mathrm{~mm}$. In subject 3, dissection of the spiral ligament by both the initial and revision electrode tracks was identified.

The bottom panels of figures 1-4 plot the percentage of extraelectrode space in the cochlear duct occupied by new bone, fibrous or inflammatory tissue and fluid as a function of distance from the round window. In an effort 


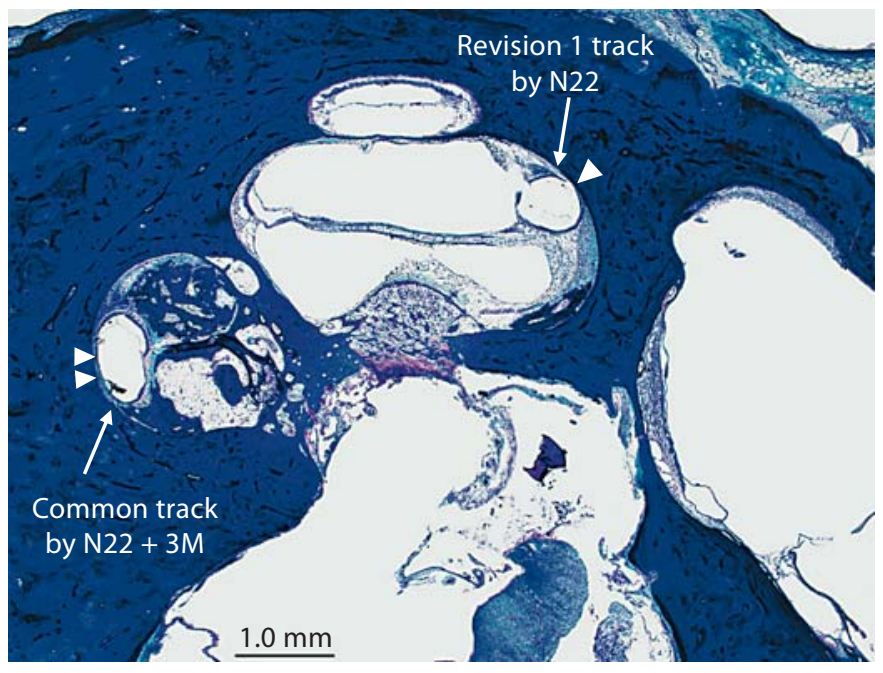

Fig. 6. Subject 1 . Horizontal section of right temporal bone. The common track in the ascending basal turn presumably had sequentially accommodated the 3M House single-channel device and then the Nucleus 22 device. The smaller track in the middle turn was caused only by the Nucleus 22 revision cochlear implant. The circumference of the common track was larger than that of the single track. Dissection of the spiral ligament (single and double arrowheads) and penetration of the basilar membrane by the electrode track (double arrowheads) were identified. N22 $=\mathrm{Nu}$ cleus $22 ; 3 \mathrm{M}=3 \mathrm{M}$ House single-channel device. Toluidine blue $\mathrm{O}$ stain.

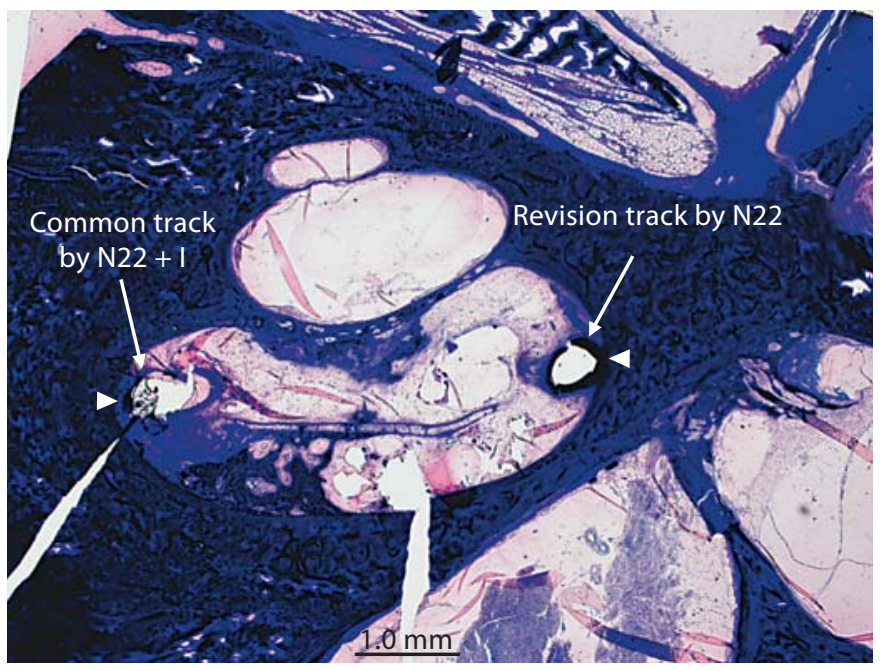

Fig. 8. Subject 2. Horizontal section of right temporal bone. The common track in the ascending basal turn was presumed to have been occupied sequentially by the Ineraid (I) and the Nucleus electrodes, and the one track in the descending basal turn, by the Nucleus $22(\mathrm{~N} 22)$ at the second-revision cochlear implantation. The common track was larger than the revision single track. Dissection of the spiral ligament (arrowheads) occurred in both tracks. Toluidine blue $\mathrm{O}$ stain.

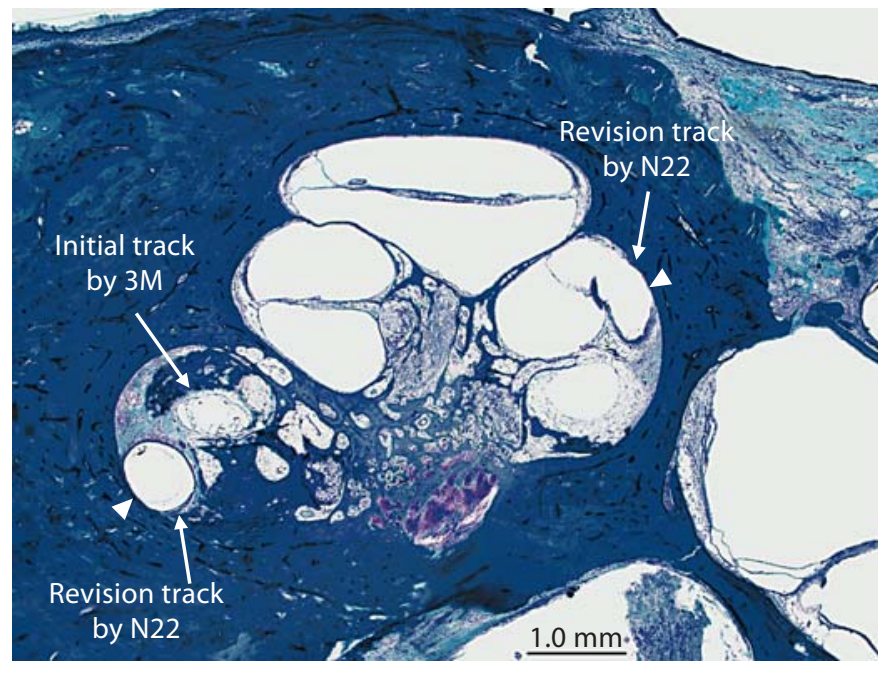

Fig. 7. Subject 1 . Horizontal section of right temporal bone. Two tracks were visible in the ascending basal turn and one track in the middle turn. The two tracks consisted of the initial track $(3 \mathrm{M}$ House single-channel device, $3 \mathrm{M}$ ) and the revision track (Nucleus 22, N22). The latter is larger than the former. Dissection of the spiral ligament to the lateral bony cochlear wall (arrowhead) was seen in both revision tracks. Toluidine blue $\mathrm{O}$ stain.

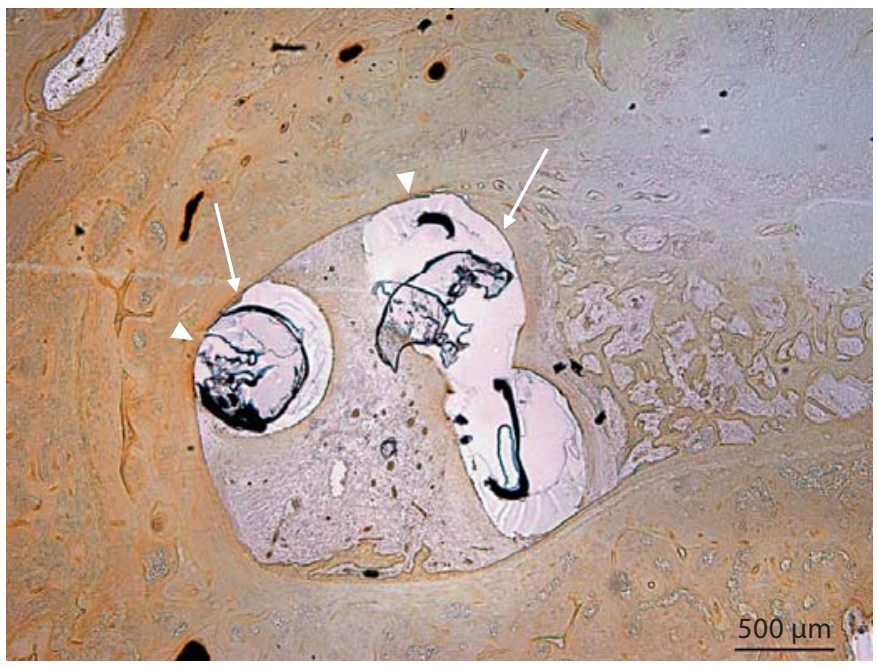

Fig. 9. Subject 3. Horizontal section of right temporal bone. In this patient, initial and revision electrodes were both Nucleus 22. The buckling of the revision electrode is visible in the basal turn (arrow). Dissection of the spiral ligament to the lateral bony cochlear wall (arrowhead) was found. The histopathologic change in the extraelectrode space in the segment containing the buckling electrode was severe ossification and no visible fibrosis or cochlear fluid space (unstained). 


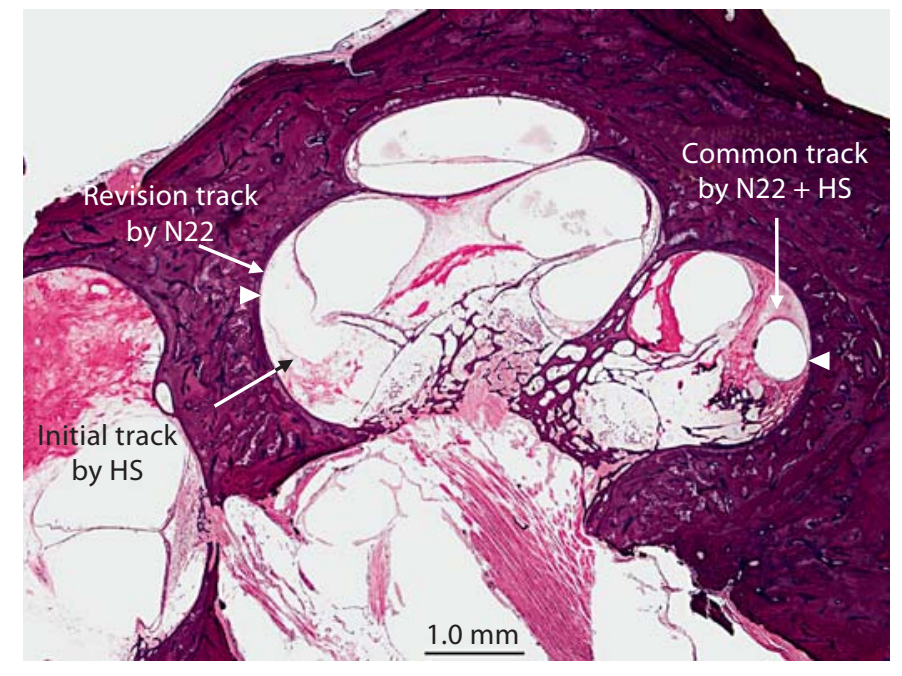

Fig. 10. Subject 4. Horizontal section of left temporal bone. The common track was visible in the ascending basal turn, and two tracks were visible in the middle turn. The two tracks consisted of the initial track (House single-channel device, HS) and the revision track (Nucleus 22, N22). The common track was larger in diameter than both single tracks. Dissection of the spiral ligament (arrowhead) occurred in the common track and in the revision single track. Hematoxylin-eosin stain.

to differentiate the amount of new bone, fibrous or inflammatory tissue caused by the cochlear implantation process from that caused by the creation of the cochleostomy, only the cochlear segments greater than $5 \mathrm{~mm}$ apical to the apical margin of the cochleostomy (apical to the vertical dashed line in the bottom panel of fig. 1-4) were included in the following analyses. Table 2 lists the weighted mean percentage (see Material and Methods) of extracochlear space occupied by new bone, fibrous or inflammatory tissue and fluid by type of electrode track and subject.

There was no significant difference between the mean (across-subject) percentages of new bone in commontrack segments (51.7\%) versus one-track segments (30.5\%) or between two-track segments (56.3\%) versus one-track segments (30.5\%). Also, there was no significant difference between the mean (across-subject) percentages of new fibrotic tissue in common-track segments (33.3\%) versus one-track segments (29.3\%) or between two-track segments (31.8\%) versus one-track segments (29.3\%). There was no significant difference between the mean (across-subject) percentages of fluid in common-track segments (15.0\%) versus one-track segments $(40.0 \%$; $\mathrm{p}=$ $0.08)$ or between two-track segments (11.8\%) versus onetrack segments (40.0\%; $\mathrm{p}=0.0598)$.

The Histopathology of Revision Cochlear Implantation
In order to determine whether cochlear segments that underwent insertion of two electrodes suffered more damage than those subjected to a single insertion, we combined the common-track results with the two-track data to form a 'two-insertion' category and we combined the new-bone and fibrotic-tissue categories to form an 'abnormal-tissue' category. We then tested whether the mean (across subject) percent area of abnormal tissue in two-insertion segments (43.3\%) was significantly different from the abnormal tissue in segments with a single track (29.9\%) and found it was not $(t=1.08$, d.f. $=13.6$, $\mathrm{p}=0.30)$.

In two-insertion segments, the mean (across subject) percent area of the extraelectrode cochlear duct filled with abnormal tissue (43.2\%) was significantly greater than the mean percent area occupied by fluid (13.4\%; $t=$ 3.12 , d.f. $=19.9, \mathrm{p}=0.003)$. But in cochlear segments with one track, the mean percent area filled with abnormal tissue $(29.9 \%)$ was not significantly different from the mean percent area occupied by fluid (40\%).

\section{Analyses Including Segments within $5 \mathrm{~mm}$ of \\ Cochleostomy}

When the cochlear segments within $5 \mathrm{~mm}$ of the cochleostomy were included in the statistical analyses, there were shifts in many of the percentages reported in the previous section, but, except for 1 case, the significant differences noted in the previous section $(\mathrm{p} \leq 0.05)$ did not change. The 1 exception was the significant difference $(t=-1.9$; d.f. $=9 ; \mathrm{p}=0.04)$ between the mean (acrosssubject) percentages of fluid in common-track segments (10.0\%) versus one-track segments (40.0).

\section{Performance after Revision Cochlear Implantation}

Word recognition scores after primary and revision implantation are displayed in table 1 . Word recognition scores for subjects 2 and 3 improved substantially after reimplantation. In the case of subject 1 , results for the before-revision time frame were not available. While the pre- and postrevision results for subject 4 are roughly consistent with no change in performance, the tests conducted before revision (closed-set words and environmental noises) are so different from the postrevision test (open-set CID sentences) that a pre/post comparison is problematic. The small number of subjects $(n=2)$ with pre- and postreimplantation performance scores did not allow statistical analysis. 


\section{Discussion}

The results of the current study support the proposition that immediate reimplantation after removal of an intracochlear electrode is likely to be successful in reaching an insertion depth of at least $19 \mathrm{~mm}$. This was the case for all 4 of the reimplanted temporal bones studied, even though (1) the preceding insertion lengths where substantially shorter than $19 \mathrm{~mm}$ in 3 cases $(12.3,13.2$ and $12.8 \mathrm{~mm})$ and (2) the last insertion in all cases followed a different track than the previous insertion in at least part of the cochlear segment first occupied by the initial electrode.

The current results are generally consistent with the results based on animal studies that histologically examined the effect of cochlear reimplantation on the inner ear. Jackler et al. [1989] performed reimplantation using either a single ball electrode or a longer electrode in 8 adult cats. They reported that cochlear explantation followed by immediate reimplantation may be accomplished without damage to the cochlea or its neural population. However, proliferation of granulation tissue at the round window and in the scala tympani may cause difficulty in insertion of the replacement device and may increase the likelihood of induced trauma. Greenberg et al. [1992] reported in the guinea pig that there was no significant difference in the pathology of singly implanted or reimplanted cochleae. However, the experimental protocol was limited to a single-wire ball-tipped intracochlear electrode. Shepherd et al. [1995] reported the histopathologic change after cochlear reimplantation using long multichannel intracochlear electrodes in the macaque, where electrode insertion trauma involving the osseous spiral lamina or basilar membrane was greater in the reimplanted cochleae and also resulted in more extensive loss of basal ganglion cells, particularly when proliferation of granulation tissue at the cochleostomy was identified. As in the current study (fig. 1-4), the cochlear damage tended to be greater in the lower basal turn.

Results from histopathological studies of reimplanted humans are available for only 5 ears. Linthicum et al. [1991] reported on 3 patients implanted first with a single platinum ball electrode that was later removed and replaced by a similar electrode. In contrast to the results of the present study, the insertion depths of all 3 reimplantations were less than the original depths. All 3 cochleae were noted to have large amounts of new bone and fibrous tissue and among the lowest ganglion cell counts compared to 16 singly implanted cochleae. Fayad et al. [2006] report an adult implant user who had undergone bilateral revision implantation, replacing a single-channel electrode $(20 \mathrm{~mm}$ in length) on one side with a Nucleus 22 multichannel device and a $3 \mathrm{M} /$ House single-channel short electrode $(6 \mathrm{~mm})$ on the opposite side with a Nucleus 24 multichannel device. Like the results of the present study, the new bone formation around the electrode path was greatest in the scala tympani of the basal turn of the cochlea. Unfortunately, the insertion depths of the reimplanted electrodes were not reported, making it impossible to compare the initial and reimplanted insertion depths for these 2 ears. The spiral ganglion cell counts were extremely low in both ears, representing less than $10 \%$ of the normal spiral ganglion cell population. Despite the low spiral ganglion cell counts, the patient derived benefit from the implants, with scores of $30 \%$ open-set word recognition and $66 \%$ on open-set sentences in both ears.

New Bone, Fibrous Tissue and Cochlear Fluid Space

Somdas et al. [2007] developed a methodology to quantitatively evaluate new bone and fibrous tissue using three-dimensional reconstruction (Amira). They evaluated 7 temporal bones and demonstrated the greatest volume of new bone formation at the cochlear base (consistent with the present results) and at sites of trauma to the lateral cochlear wall in the ascending limb of the basal turn. They suggested that trauma to the endosteum or lateral cochlear wall may be a factor in induction of this tissue reaction.

By using a scoring system for damage to the lateral cochlear wall and a three-dimensional reconstruction method, Li et al. [2007] evaluated new bone and new fibrous tissue formation in the inner ear following cochlear implantation in 12 temporal bones. In addition to finding new bone being most prevalent in the base (consistent with the findings of the current study), they reported a significant correlation between total damage to the lateral cochlear wall and total volume of new bone, new fibrous tissue and total new tissue. They suggested that insertion trauma to the lateral cochlear wall may play a role in subsequent fibrosis and neo-ossification following cochlear implantation. High levels of osteoprotegerin within the spiral ligament may serve to inhibit bone remodeling, and exposure of the underlying endosteum may provide a nidus of inflammation to promote ossification. Inflammatory mediators may contribute to a general increase in new bone formation.

\section{Revision Insertion Depth and Performance}

Our observation that the depths of insertion of the reimplanted electrodes were all deeper than the initial depths of insertion is consistent with the reports of supe- 
rior performance after revision cochlear-implant surgery using multichannel electrodes and a low percentage of perioperative complications [Buchman et al., 2004; Cullen et al., 2008; Rivas et al., 2008]. Lassig et al. [2005] reported on 58 cochlear reimplantations. Electrode insertion depth was equal or deeper in 53 of 58 cases. Of the 35 patients for whom comparison data are available, speech recognition scores after reimplantation were as follows: improved in 25 (71.4\%), little or no change in 7 (20.0\%) and decreased in $3(8.5 \%)$. Coté et al. [2007] reported on 45 cochlear implant revisions. Electrode reinsertion depth was comparable with that at the initial surgery, with full reinsertion with the same type of electrode array as in the primary implantation in $33(76.7 \%)$ cases. But in 3 cases (7.0\%) only partial insertion was achieved at revision surgery despite complete insertion during the initial implantation. Speech perception was maintained after reimplantation. Of the 19 children with available data, 5 had higher scores after the revision surgery, 12 had similar scores, and only 2 had lower scores. Gosepath et al. [2009] reported on 56 surgical revisions of cochlear implantation. In all revisions, the electrode insertion depth at the time of reimplantation was similar to that at the initial implantation. In 20 cases in which speech audiometry data were available, 19 showed similar or better scores than before reimplantation.

While the speech reception data of the current study are consistent with the results reviewed in the previous paragraph, the small number of subjects $(n=2)$ with preand postreimplantation performance scores does not support a statistical analysis.

\section{Conclusions}

(1) Results of the current study support reimplantation when there is reason to think advisable (e.g. the original implantation was inadequate, the implanted device is malfunctioning or an improved device is available). In the current study, the depth of insertion of a cochlear-implant electrode array at reimplantation was not limited by the depth of insertion of the initial implant. In all 4 cases, the depth of insertion of the final implant was greater than that of the initial implant. The revision electrode did not always share the previously formed track but diverged from the common track for at least a short distance to create a new track in each of the 4 bones studied.

(2) There was no significant difference between the mean percent area of abnormal tissue in segments with a common or two tracks (43.3\%) and segments with a single track (29.9\%).

(3) In cochlear segments with a common or two tracks, the mean (across-subject) percent area of the extraelectrode cochlear duct filled with abnormal (new bone, fibrotic or inflammatory) tissue (43.2\%) was significantly greater than the mean percent area occupied by fluid $(13.4 \% ; \mathrm{t}=3.12$, d.f. $=19.9, \mathrm{p}=0.003)$.

(4) In cochlear segments with one track, the mean percent area filled with abnormal tissue (29.9\%) was not significantly different from the mean percent area occupied by fluid (40\%).

\section{References}

Buchman CA, Higgins CA, Cullen R, Pillsbury HC: Revision cochlear implant surgery in adult patients with suspected device malfunction. Otol Neurotol 2004;25:504-510.

Coté M, Ferron P, Bergeron F, Bussières R: Cochlear reimplantation: causes of failure, outcomes, and audiologic performance. Laryngoscope 2007; 117:1225-1235.

-Cullen RD, Fayad JN, Luxford WM, Buchman CA: Revision cochlear implant surgery in children. Otol Neurotol 2008;29:214-220.

- Fayad JN, Baino T, Parisier SC: Revision cochlear implant surgery: causes and outcome. Otolaryngol Head Neck Surg 2004;131:429432.
Fayad JN, Eisenberg LS, Gillinger M, Winter M Martinez AS, Luxford WM: Clinical performance of children following revision surgery for a cochlear implant. Otolaryngol Head Neck Surg 2006;134:379-384.

Gosepath J, Lippert K. Keilmann A, Mann WJ: Analysis of fifty-six cochlear implant device failures. ORL J Otorhinolaryngol Relat Spec 2009;71:142-147.

Greenberg AB, Myers MW, Hartshorn DO, Miller JM, Altschuler RA: Cochlear electrode reimplantation in the guinea pig. Hear Res 1992;61:19-23.

Guild SR: A graphic reconstruction method for the study of the organ of Corti. Anat Rec 1921;22:141-157.

-Henson AM, Slattery WH III, Luxford WM, Mills DM: Cochlear implant performance after reimplantation. A multicenter study. Am J Otol 1999;20:56-64.
Jackler RK, Leake PA, McKerrow WS: Cochlear implant revision: effects of reimplantation on the cochlea. Ann Otol Rhinol Laryngol 1989;98:813-820.

Kang SY, Zwolan TA, Kileny PR, Niparko JK, Driscoll CL, Shelton C, Telian SA: Incomplete electrode extraction during cochlear implant revision. Otol Neurotol 2009;30: 160-164.

Lassig AA, Zwolan TA, Telian SA: Cochlear implant failures and revision. Otol Neurotol 2005;26:624-634.

Li PMMC, Somdas MA, Eddington DK, Nadol JB Jr: Analysis of intracochlear new bone and fibrous tissue formation in human subjects with cochlear implants. Ann Otol Rhinol Laryngol 2007;116:731-738. 
Linthicum FH Jr, Fayad J, Otto SR, Galey FR, House WF: Cochlear implant histopathology. Am J Otol 1991;12:245-311.

- Miyamoto RT, Svirsky MA, Myres WA, Kirk KI, Schulte J: Cochlear implant reimplantation. Am J Otol 1997;18:S60-S61.

Nadol JB Jr: Quantification of human spiral ganglion cells by serial section reconstruction and segmental density estimates. Am J Otolaryngol 1988;9:47-51.

- Nadol JB Jr, Ketten DR, Burgess BJ: Otopathology in a case of multichannel cochlear implantation. Laryngoscope 1994;104:299303.
Rabinowitz WM, Eddington DK, Delhorne LA, Cuneo PA: Relations among different measures of speech reception in subjects using a cochlear implant. J Acoust Soc Am 1992;92: 1869-1881.

Rivas A, Marlowe AL, Chinnici JE, Niparko JK Francis HW: Revision cochlear implantation surgery in adults: indications and results. Otol Neurotol 2008;29:639-648.

Rubinstein JT, Parkinson WS, Lowder MW Gantz BJ, Nadol JB Jr, Tyler, RS: Single-channel to multichannel conversions in adult cochlear implant subjects. Am J Otol 1998;19: 461-466.

Schuknecht HF: Pathology of the Ear, ed 2. Philadelphia, Lea \& Febiger 1993, pp 1-29.

-Shepherd RK, Clark GM, Xu SA, Pyman BC: Cochlear pathology following reimplantation of a multichannel scala tympani electrode array in the macaque. Am J Otol 1995;16 186-199.
Somdas MA, Li PMMC, Whiten DM, Eddington DK, Nadol JB Jr: Quantitative evaluation of new bone and fibrous tissue in the cochlea following cochlear implantation in the human. Audiol Neurotol 2007;12:277-284.

Sorrentino T, Coté M, Eter E, Laborde M, Cochard N, Deguine O, Fraysse B: Cochlear reimplantations: technical and surgical failures. Acta Otolaryngol 2009;129:380-384.

Zeitler DM, Budenz CL, Roland JT Jr: Revision cochlear implantation. Curr Opin Otolaryngol Head Neck Surg 2009; 17:334-338. 